\title{
Obituary
}

\section{Tolani Asuni}

\section{Formerly Professor of Psychiatry, University of Ibadan, Nigeria}

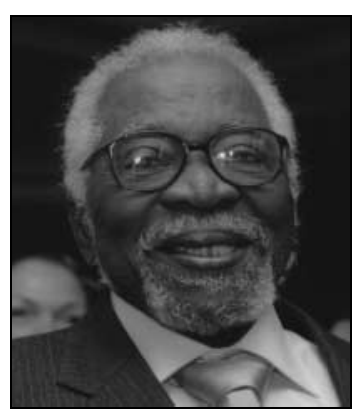

Tolani Asuni was born 6 January 1924 in Lagos, Nigeria. He was educated at Baptist Academy and Igbobi College, both in Lagos. He studied medicine at Trinity College Dublin (1945-1951) and trained as a psychiatrist at The Maudsley and the Institute of Psychiatry, London (1957-1960). He was elected FRCPsych in 1970. His life and contributions to medicine and psychiatry paralleled the history of Nigeria from the colonial to the post-colonial periods.

Tolani Asuni was proud of his association with Dublin, where he made many friends and had an 'adoptive' family, the Wilkies. He was particularly proud of his clinical training at Baggot Street Hospital (now the Royal City of Dublin Hospital) where he functioned both as a student and a houseman. When he returned to Nigeria in 1953, he was employed by the colonial medical service, first as a medical officer serving at the General Hospital Lagos, and later as rural medical officer at Oyo, Shagamu and Badagry. In these roles he acted as general practitioner, anaesthetist, general surgeon and gynaecologist. His account of medical practice in the 1950s is a reminder of the scarcity of resources during the colonial period as well as of the ingenuity that was required to provide the most basic care of patients. For example, he operated under a bush lamp, improvised uterine clamps, and was ably assisted by nurses as his anaesthetists.

As a medical student, Asuni had joined the Monkstown Group, a lay psychoanalytical group led by Jonathan (Jonty) Hanaghan that met weekly on Saturday evenings. He received his analysis from Rupert Strong and was probably the first African analysand. Despite this, following graduation, his first intention was to train as an ear, nose and throat surgeon and it was fortuitous that he became a psychiatrist. In 1956, Thomas Adeoye Lambo, the first Nigerian psychiatrist, met Asuni when on holiday and enquired whether he would be interested in taking up psychiatric training. That exchange resulted in Asuni's change of career.

On Lambo's departure from the Neuropsychiatric Hospital Aro, Abeokuta, where he had developed a village system of community care, to become the foundation professor of psychiatry at University College Hospital Ibadan, Asuni became medical superintendent. Under his management, the hospital became an established teaching centre for medical students from Ibadan, consolidated the village system of community care and became a World Health Organization collaborative centre. Asuni became Professor of Psychiatry at Ibadan and later at Lagos. He was Director of the United Nations Social Defence Research Institute, Rome, from 1979 to 1984 , and worked in many other capacities in Nigeria including chairman of the Psychiatric Hospitals Management Board and Chief Examiner at the Faculty of Psychiatry, West African College of Physicians.

Alongside his clinical and administrative commitments, Asuni was also a researcher. In his seminal publication on suicide in Western Nigeria (BMJ, 1962), he discovered that the coroner's verdict of suicide was 1 in 100000 cases, a figure markedly lower than that in Western Europe. The rate was increased in males, the elderly, socially isolated individuals and Christians. In a later report on homicides in Western Nigeria (British Journal of Psychiatry, 1969), he showed that the rate was 1.6 per million, again markedly lower than in Western Europe and North America, and there were no cases of psychopathy or homicide followed by suicide in his series. These two studies epitomised Asuni's approach: methodical, careful and restrained in finding his conclusions. He made important contributions to the development of criminology as a discipline in the African continent and was partly responsible for the setting up of an African Regional Institute in Kampala, Uganda. His textbook, Mental Health and Disease in Africa (Churchill Livingstone, 1975), jointly written with Charles Swift, was for over 30 years the only text for undergraduates and postgraduates on the subject. The latest edition by Asuni and Schoenberg continues to be an important source of knowledge about clinical psychiatry in the African context.

Tolani Asuni died on 21 June 2011.

Femi Oyebode

doi: 10.1192/pb.bp.111.037440 